\title{
Student Satisfaction: Importance of Civility and University Identification Predictors
}

\author{
LaVelle Hendricks ${ }^{1}$, Stephen Reysen ${ }^{2}$, Zaidy Mohdzain ${ }^{3}$, Kelly Martin ${ }^{4}$, Joy Teles Oliveira ${ }^{5}$ \& Quynh Dang ${ }^{6}$ \\ ${ }^{1}$ Associate Professor of Counseling, Texas A\&M University-Commerce, Commerce, USA \\ 2 Associate Professor of Psychology, Texas A\&M University-Commerce, Commerce, USA \\ ${ }^{3}$ Chair and Professor of Counseling, Texas A\&M University-Commerce, Commerce, USA \\ ${ }^{4}$ Research Assistant, Department of Psychology, Texas A\&M University-Commerce, Commerce, USA \\ ${ }^{5}$ Research Assistant, Department of Counseling, Texas A\&M University-Commerce, Commerce, USA \\ ${ }^{6}$ Assistant Professor of Health and Human Performance, Texas A\&M University-Commerce, Commerce, USA \\ Correspondence: LaVelle Hendricks, Associate Professor of Counseling, Texas A\&M University-Commerce, \\ Commerce, USA. E-mail: LaVelle.Hendricks@tamuc.edu
}

Received: August 31, 2020

doi:10.5430/irhe.v5n4p1
Accepted: September 31, 2020

Online Published: January 13, 2021

URL: https://doi.org/10.5430/irhe.v5n4p1

\begin{abstract}
Uncivil behavior has recently been a topic of concern within university campuses. Administration, faculty, and students are all subject to engage or experience uncivil conduct. Academic civility is a fundamental variable to establish a positive university environment and teaching-learning outcomes. Objective: The present paper analyzes the concept of civility and incivility within an academic context, offers a dimension perspective of the problem, reviews contributing factors associated with incivility, explores preventative measures for incivility, investigates academic strategies that promote civility, and makes recommendations for intervention strategies. A study that examines relationships between civility, university identification and satisfaction with the university was conducted. Methods: undergraduate students $(\mathrm{N}=588)$ from a state university answered a survey that evaluated three variables: civility, university identification, and university satisfaction. Results: Civility was positively related to university identification $(r=.11, p=.009)$ and satisfaction $(r=.16, p<.001)$, and identification was related to greater satisfaction with the university $(r=.75, p<.001)$. Conclusion: Greater levels of civility are correlated with university identification and satisfaction. In order to improve teaching-learning environments, academic institutions are encouraged to promote an environment that is conducive to civility, as well as establish civil behaviors as part of their instruction.
\end{abstract}

Keywords: civility, incivility, academic civility, university satisfaction, university identification

The topic of civility, or lack there of, has generated a great deal of interest recently, in the research literature, political discourse, and mainstream news coverage (Spencer, Tyahur, \& Jackson, 2016). Plante (2017) reported that demeaning, insulting, and even aggressive behaviors appear to be much more commonplace and normalized throughout the various media platforms (i.e., social media, talk radio, cable news, etc.), noting that "even well-known leaders in politics, athletics, entertainment, and business engage in and are often reinforced for incivility" (p. 401). Civility is a broader concern in society and in work environments more specifically, where uncivil behaviors frequently occur across a variety of occupations, ranging from healthcare to law, in addition to academia (Baker, Comer, \& Martinak, 2008).

Incivility in the college classroom is reported to be on the rise (Morrissette, 2001; Weeks, 2011), leading to less than optimal teaching-learning environments for both faculty and students (Segrist, Bartels, \& Nordstrom, 2018). While not all involved behave rudely, occurrences of uncivil behavior are sufficiently pervasive to garner significant concern from the academic community (Price, 2010), resulting in a growing trend of civility initiatives, including campus-wide campaigns, instituting civility codes of conduct, teaching character education in first-year college classrooms, and offering faculty training on how to address uncivil behaviors (Baker et al., 2008). A true appreciation of the concept of academic civility and its counterpoint (incivility), is predicated on understanding the broad spectrum of meaning attributed to each construct, the behaviors associated with various typologies (i.e., 
student-to-faculty, faculty-to-student, etc.), and how these behaviors impact faculty, students, and education at large (Robertson, 2012). The purpose of this paper is to offer a primer on this growing problem, as mentioned above, in addition to reviewing contributing factors associated with incivility, and making recommendations for intervention strategies.

\section{Defining the Concepts}

Civility. Civility as a construct is inconsistently conceptualized in the research literature and well known to cover a broad spectrum of meaning. For example, Forni (2002) reported forty-two different terms/phrases connected with civility. While the concept resists easy classification, definitions tend to reflect one of three broad themes: (a) manners/politeness; (b) awareness, acknowledgement, and respect for others; and (c) participation in the democratic process (Spencer et al., 2016). Spencer et al. (2016) suggests that simply categorizing civility as mere politeness not only undersells the importance of the concept, but also neutralizes its message to something as benign as "be kind."

Civility is most commonly discussed as a virtue, combining both manners/politeness (i.e., behaviors) and moral principles centered on the importance of human dignity and valuing the inherent worth of each person (Connelly, 2009). In other words, civility as a virtue is a capability, habit, or character trait that can be learned. Williams \& Lauerer (2013) suggest that academic institutions bear the responsibility to set the stage for students' future professional behaviors, such as behaving civilly in the workforce. Connelly (2009) concurs, suggesting faculty needs to assume some responsibility "for being the intentional transmitters of ...values that compose academic civility" (p. 57); however, cautions that civility may at times require individuals to curtail their personal freedoms for the common good, much to the dismay of many. Calls for civil behavior have been used by persons in power, both historically and presently, as a way to maintain the status quo and to keep certain groups in a place of subservience (Connelly, 2009). Callahan (2011) suggested that organizations tend to codify civility, attempting to control what they deem as deviant behavior, when they "feel threatened by the emotionally-driven actions of those less powerful" (p. 12). Nevertheless, Spencer and associates (2016) urge people to not use this as an excuse to normalize uncivil behavior instead.

On the contrary, many aspire toward a broader vision of civility that includes whatever strategies enable and enact healthy and robust democratic deliberation (Dishon \& Ben-Porath, 2018; Spencer et al., 2016). Connelly (2009) suggested that civility at it's most authentic is infused with integrity, and as such, may at times "necessitate civil disobedience that challenges the powers that be," (p. 54) much like the peaceful protests of the Civil Rights Movement. Spencer et al. (2016) propose that no adequate definition of civility would exclude minorities or marginalized populations, silence unpopular opinions, or shy away from conflict, but that true civility would acknowledge the power differentials in the world, and permit various forms of protest, making space for the freedom of expression granted by the First Amendment of the United States Constitution. This type of civility, they offer, has progressive power, allowing a multitude of voices to explore their differences respectfully and disagree civilly. The authors acknowledged, however, the difficulty college campuses face in fostering diversity and inclusiveness while also encouraging free expression (Spencer et al., 2016). Therefore, to encourage a better understanding of what civil behavior entails, Plante (2017) operationally defined civility as the following behaviors:

- "Think carefully before speaking.

- Differentiate and articulate facts from opinions.

- Focus on the common good.

- Disagree with others respectfully.

- Be open to others without hostility.

- Respect diverse views and groups.

- Offer a spirit of collegiality.

- Offer productive and corrective feedback to those who behave in demeaning, insulting, disrespectful, and discriminatory ways.

- Create a welcoming environment for all.

- Focus corrective feedback on one's best and most desirable behavior" (p. 403).

Callahan (2011) stresses the importance of understanding the concepts of "civility" and "incivility" as socially constructed labels for what constitutes "acceptable" and "unacceptable" expression of emotion/behaviors. While "civility is fundamentally about the moral and cultural codes that guide people with regard to how to behave properly 
in public...incivility is defined differently by those occupying different power status positions" (Callahan, 2011, p. 13). Callahan went on to describe what is sometimes construed as uncivil behavior to those in power is really a valid attempt to initiate needed change; the powerless often describe their behavior as resistance, while the powerful label it incivility (2011).

Incivility. Definitions of incivility in higher education are generally based on student behaviors and are united by several common threads: behaviors indicative of disrespect (i.e., spoken words, gestures, or actions), which vary greatly in disruptiveness (e.g., texting vs. talking on a phone) and harmfulness (listening to headphones vs. insulting another student), and interfere with a harmonious and cooperative learning atmosphere in the classroom (Boysen, 2012; Corbett, 2019; Robertson, 2012; Segrist et al., 2018). Andersson and Pearson (1999) noted that intent to harm is often ambiguous as well. Uncivil behavior is often delineated into four broad types of actions from the less serious to most severe offenses (Connelly, 2009; Corbett, 2019), including (a) annoyances such as answering a cell phone or doing homework for another course; (b) classroom terrorism acts such as intolerance of others' opinions or derailing a classroom discussion; (c) intimidation which includes threatening to complain about an instructor to superiors, and (d) enacted or threatened violence toward others (Feldmann, 2001).

Alternatively, Ward and Yates (2014) citing Alexander, Mundrake, and Brown (2009) divided student incivility into three types: personal, technical, and collaborative. The authors describe personal incivility as behaviors enacted by a sole perpetrator including arriving late to class, reading non-class materials, falling asleep, or talking while the instructor is lecturing; technical incivility encompasses behaviors related to technological (i.e., cell phone, computer, etc.) misuse including browsing the web, playing video games, or accessing social media during instruction; and collaborative incivility concerns uncivil behaviors that involve more than one perpetrator, such as handing in someone else's work as his/her own, working as a group on individual assignments, or receiving help on a test from another student (Ward \& Yates, 2014).

Regardless of categorical delineation, however, the rude and disruptive behaviors associated with incivility often result in physiological and/or psychological distress (Corbett, 2019), not only for targets but also witnesses (Baker et al., 2008). Furthermore, incivility - which could also meet the criteria for resistance - is often an indicator of structural problems of inequity at the organizational level, and signal the need to explore and address more challenging issues, such as abuses of power (Callahan, 2011). Incivility is complex in nature, which makes it a challenge to identify. To remedy this, Corbett (2019) citing Clark (2017) offered twelve indicators one might consider to identify social interactions that contextualize uncivil behavior:

- "You feel physically sick or emotionally upset before going to work or school.

- You are the target of rude remarks, insults, or put-downs.

- You are belittled, humiliated, or demeaned (often in front of others).

- You are excluded, isolated, or marginalized from work, school, or social activities.

- You are the object of teasing or practical jokes.

- You are the target of gossip, rumors, or other types of offensive speech or behavior.

- You are unreasonably overloaded with work or seemingly impossible deadlines.

- You are deliberately denied information and resources to be successful at work or school.

- Coworkers/supervisors intentionally withhold important information needed to perform well in your job.

- You have been unsupported by a coworker/supervisor and set up to fail.

- You have been intentionally neglected, marginalized, or excluded.

- Confidences that you have shared have been breached or shared without your permission" (p. 7).

Typologies. Rawlins (2017) reported a variety of typologies associated with academic incivility (i.e., student-to-faculty, faculty-to-student, student-to-student and faculty-to-faculty) and stressed that the two main types, student-to-faculty and faculty-to-student incivility, are intricately linked, often by way of an "incivility spiral" (Andersson \& Pearson, 1999). A negative norm of reciprocity exists where individuals tend to reciprocate aggression with counter-aggression (Helm, Bonoma, \& Tedeschi, 1972). In other words, unprofessional, rude behaviors elicit similar behaviors in return, with both students and faculty contributing to an overall climate of disrespect for one another (Ghosh, Dierkes, \& Falletta, 2011; Frey Knepp, 2012; Rawlins, 2017). 
Student-to-faculty. Connelly (2009) cited a study conducted at Indiana University (Center for Survey Research, 2000) based on faculty perceptions of student incivility in the classroom. Faculty listed a range of uncivil behaviors, with less serious acts including disapproving groans, acting bored or apathetic, sleeping in class, and demanding makeup exams/extensions or grade changes to more serious acts such as cheating on exams, harassing comments in and out of class, hostile challenges directed at professor, and threats of physical harm (Connelly, 2009). A large-scale study investigating student perceptions of classroom incivility found that students perceive a fair amount of moderately uncivil behavior on a regular basis as well (Bjorkund \& Rehling, 2009). Some of the more serious behaviors reported include students who continue to talk after being asked to stop, coming to class under the influence of drugs/alcohol, allowing their cell phone to ring repeatedly, and showing disrespect for others nonverbally; however, the most frequently observed uncivil behaviors were considered less severe (e.g., text messaging, packing up books before class is over, arriving late or leaving early; Bjorkund \& Rehling, 2009). Ausbrooks, Jones, and Tijerina (2011) conducted a study comparing faculty and student perceptions of incivility in the classroom and found that generally, faculty perceived incivility as less serious and less frequently occurring, compared to student perceptions, but reported that the groups' ratings were comparable overall when it came to assessing the seriousness of specific behaviors, should they occur. The authors added that students still perceived a greater frequency of these specific behaviors and noted that faculty may not be aware of the multitude of occurrences happening in their classrooms due to their primary focus on instruction (Ausbrooks et al., 2011).

Faculty-to-student. While classroom incivility is often discussed from a faculty perspective, suggesting student-to-faculty incivility is a fairly common finding across academic settings, research has shown that instructors' engagement in incivility-faculty-to-student incivility, which refers to discourteous behaviors directed from educators to students - is also on the rise (Frey Knepp, 2012; Rawlins, 2017). Faculty often contribute to academic incivility, and their behaviors are noticed and reported by students as well (Frey Knepp, 2012; Rawlins, 2017). Learning environments are social in nature, and as such, "impact what learners retain, how they form ideas, and what connections are made/lost when acquiring new skills/knowledge" (Stork \& Hartley, 2009, p. 13). Instructors, as the most socially dominant in a classroom (Stork \& Hartley, 2009), carry a heavier burden to remain aware of their own uncivil conduct because students, generally in a subordinate position, already have diminished opportunities for speaking and participating in the classroom (Dishon \& Ben-Porath, 2018).

Connelly (2009) reported six common themes across the most frequently occurring faculty-to-student uncivil behaviors including, "condescending remarks, poor teaching style/methods, poor communication skills, acting superior/arrogant, criticizing students in front of peers, and threatening to fail students" (p. 49). Other examples of faculty-to-student incivility include: changing the course syllabus, lecturing too fast without enough student interaction, making up rules as they go along, coming up with unexpected test items/grades, being unfair and rigid, insisting on conformity, discriminating based on gender, race, ethnicity, expressing political bias (Connelly, 2009). Stork and Hartley (2009) categorized faculty-to-student incivility into three groups: least offensive, moderately offensive, and most offensive. Examples are as follows:

- Most offensive faculty behaviors:

○ Intimidating, humiliating, or embarrassing students (including veiled/unveiled threats),

○ Flirting with/“hitting on" a student/commenting on student's looks,

- Not helping students when assignments or tasks are unclear to them,

- Not grading assignments in timely manner/keeping class overtime,

- Degrading or criticizing other professors,

- Moderately offensive:

- Not making class interesting,

- Coming late to class/appearing disorganized,

- Cancelling class without prior notice,

- Reading PowerPoint slides/lecturing entire class period,

- Talking to fast/too slow/not loud enough/too loudly,

- Least offensive

$\circ$ Drinking beverage while teaching, 
○ Ending class early,

- Grading on curve,

○ Offering strong opinions,

○ Talking about personal life (Stork \& Hartley, 2009).

Faculty-to-student mentoring relationships are also subject to incidences of incivility (Ghosh et al., 2011). Ghosh and associates (2011) detail mentor characteristics and interaction behaviors that limit their ability to effectively provide guidance to mentees/students. The list includes distancing behaviors such as paying little to no attention to developing mentees' skills/career and manipulative behaviors (i.e., abuses of power for mentor's gain) such as inappropriate delegation, credit taking, and sabotage; in addition to general dysfunctionality and lack of expertise (Ghosh, et al., 2011).

Faculty-to-faculty. Faculty-to-faculty incivility, like other kinds of workplace incivility, is also a cause for concern. Behaviors reported to be most nefarious include, making rude remarks, put-downs, personal attacks, or threatening comments, that often include racial/ethnic, sexual/gender, or religious slurs; setting people up to fail; withholding vital information necessary to perform job duties; and abusing one's position of authority (Clark, Olender, Kenski, \& Cardoni, 2013). Faculty-to-faculty incivilities that occur most frequently included, failing to perform one's share of the workload, unwillingness to change, refusing to listen/communicate on work-related issues, distracting self and others by using technological devices during meetings, making rude comments or put-downs, and engaging in secret, closed-door meetings to exclude individuals (Clark et al., 2013).

\section{Significance of the Problem}

Incivility, regardless of type, can "interfere with classroom learning, harm the learning environment, and weaken students' respect for and attachment to their institutions" (Bjorkund \& Rehling, 2009, p. 15), in addition to being detrimental to individual health and well-being (Rawlins, 2017). Both students and faculty experience emotional effects (e.g., feelings of helplessness, anger, and frustration), psychological effects (e.g., anxiety, and depressive symptoms), and physical effects (e.g., increasing bodily complaints, and loss of sleep), in response to experiencing incivility, and these effects have a long-lasting negative impact (Rawlins, 2017).

For students more specifically, the physical and psychological impact of incivility is associated with student disengagement, while also decreasing motivation to learn, and increasing intention to leave their program of study (Rawlins, 2017). Students also tend to avoid faculty and fail to seek help when necessary, negatively impacting academic achievement, due to feelings of fear and intimidation, and loss of respect for instructors who engage in uncivil behaviors (Rawlins, 2017). Stork and Hartley (2009) noted that the emotional distress and resentment associated with experiencing acts of incivility "hampers brain organization of new information," further disrupting the learning process for students (p. 23).

Similar to incivility in the workplace, faculty may experience symptoms of burnout such as loss of morale, leading to effort reduction, increased absenteeism, and even resignation (Leiter, Laschinger, Day, \& Oore, 2011; Rawlins, 2017). Student incivility frequently occurs when faculty provide student performance evaluations and exam/assignment grades; some faculty may avoid providing necessary student feedback for fear of ensuing conflict and negative student-teacher evaluations (Rawlins, 2017). This ultimately hurts students, by preventing opportunities for growth. Instructors also complain about lack of administrative support and significant amounts of wasted out-of-class time spent documenting student incivility, which could be better spent preparing course materials and supporting students (Rawlins, 2017).

\section{Contributing Factors}

Roberson (2012) described incivility as "analogous to a syndrome, in that its etiology or cause can be traced to a constellation of coexisting problems" whose "additive effect (of multiple aggravating factors) threatens the viability of the educational process" (p. 25). Put differently, multiple interrelated factors contribute to the complexity that is academic incivility, including facilitators at the institutional, student, and faculty levels.

Institution-related. A paradigm shift has taken place within higher education over the last two decades with academic institutions embracing a business model in which they, the suppliers of educational products, are in constant competition to attract consumer dollars, causing them to evaluate potential students with an eye to the bottom line, which has led to rapid diversification across college campuses (Baker et al., 2008; Dalton \& Crosby, 2010; Frey Knepp, 2012). According to Clauson and McKnight (2018), “A recent report from the National Center for Education Statistics (NCES) cites increases in college attendance among every racial minority group between 
1976 and 2015" (p.39). This changing student population brings a broad array of attitudes and expectations about learning (Frey Knepp, 2012) and creates unique assimilation problems necessitating the development of a wide variety of services, programs, and policies in order to create respectful, tolerant, welcoming campuses (Dalton \& Crosby, 2010). Universities continue to grow in size, with bloated, impersonal classes, leaving students feeling more like a number than individual learners (Frey Knepp, 2012). Attending college, however, is no longer considered an option but a necessity for the purpose of attaining higher paying jobs (Dalton \& Crosby, 2010; Price, 2010), resulting in many students viewing higher education as simply a means to an end or an experience they must endure (Frey Knepp, 2012).

Student-related. Many of today's students are academically challenged before being admitted to college, bringing with them lenient expectations from high school, permissive parents, a regular diet of instant gratification entertainment, short attention spans, a sense of entitlement, and a desire to be entertained in class rather than wanting to acquire knowledge for its own sake (Corbett, 2019; Frey Knepp, 2012). Additionally, students are often juggling multiple life roles and work demanding full- or part-time jobs, in addition to taking a full course load; nontraditional students have the added weight of familial responsibilities as well (Frey Knepp, 2012; Robertson, 2012). There is tremendous pressure to perform amidst significant time constraints, and students often possess inadequate or maladaptive coping skills (Frey Knepp, 2012; Robertson, 2012). Stork and Hartley (2009) suggested that students might have differing perceptions about what constitutes faculty incivility depending on how well they cope with multiple stressors. Robertson (2012) reported, however, that in general, the increased stress and anxiety students face, sets in motion a cycle of fear breeding desperation, and exhaustion leading to impulsivity, impaired judgment, and increasing incivility.

Ausbrooks and associates (2011) propose that generational differences between students (Millennials, GenMe, or GenY) and faculty (Baby Boomers and Generation X) contribute to academic incivility as well; however, extant research on this purported causal relationship has yielded mixed findings (Robertson, 2012). Still, many emphasize the need to manage intergenerational diversity in the academic environment, given differences in perceptions of incivility across generational lines (Ausbrooks et al., 2011; Baker et al., 2008).

Nature of Millennials. Millennials, born between 1982 and 2000, are more racially and ethnically diverse than any previous American generation (Baker et al., 2008), and embody a unique blend of characteristics that contribute to incivility on college campuses, which include: close family and community ties, disillusionment with authority figures, peer-centrism, need for achievement, increasing individualism, digitalism, and educational consumerism (Ausbrooks et al., 2011; Baker et al., 2008; Dalton \& Crosby, 2010). Millennials' parents tend to be overly involved in their lives, extending adolescence and delaying development of independence, which results in poor problem solving skills and lack of experience as decision-makers (Baker et al., 2008; Price, 2010). Today's college students are less knowledgeable about and less engaged in civic participation (e.g. less likely to vote), due to disillusionment with politics, leaders, and authority figures overall (Dalton \& Crosby, 2010; Dishon \& Ben-Porath, 2018). While Millennials care more about the opinions of peers than that of authority figures, they still internalize parental pressure to earn good grades and expect to receive the same degree of attention and assistance in college as they did at home (Baker et al., 2008).

Increasing individualism. Twenge (2010) reported increases in individualistic traits such as self-esteem, assertiveness, and narcissism among American college students with the most rapid ascension co-occurring with Millennials reaching college-age (Bourke \& Mechler, 2010). Narcissistic individuals tend to be self-interested, lack empathy, and have a sense of entitlement, often holding unrealistic expectations for favorable treatment (Ausbrooks et al., 2011). Parents offered their millennial children praise and rewards for mediocre and substandard performance, which created the expectation in them that colleges would follow suit (Ausbrooks et al., 2011). Students frequently expect good grades, even undeservedly (e.g., for simply attending class), and blame instructors if they do not succeed (Ausbrooks et al., 2011). Many students expect instructors to bear the responsibility for student learning, taking a more passive role in their own education (Ausbrooks et al., 2011; Frey Knepp, 2012). Nordstrom, Bartels, and Bucy (2009) found that narcissistic students were more likely to engage in academic incivility.

Digitalism. Millennials were the first generation to grow up with cellphones, email, video streaming, social media, and the Windows operating system and are often known as wired multitaskers, believing they can e-multitask (e.g., play video games while studying for an exam) without negatively impacting their performance (Baker et al., 2008). They tend to have a low tolerance for delay and act impatiently with technology that doesn't work well, due to being raised in an age where information and communication are readily available, anytime, anywhere (Bartlett \& Bartlett, 2016; Price, 2010). This level of hyperconnectivity promotes inattention and distraction (Frey Knepp, 2012), while 
also decreasing face-to-face contact/communication necessary to develop adequate social skills (Bartlett \& Bartlett, 2016). Bartlett and Bartlett (2016) noted that students might feel a false sense of anonymity when using technology-assisted communication, acting in ways they would not if they were interacting in-person, which could ultimately lead to acts of incivility.

Educational consumerism. Coinciding with academic institutions endorsing a business model, Millennials and their parents have adopted a consumer orientation to education, shifting the balance of power between faculty and students (Ausbrooks et al., 2011; Baker et al., 2008; Robertson, 2012). College professors are no longer automatically given respect as experts in their respective fields, but are perceived by some as merely employees to which students pay their salary, and therefore, can treat as they wish, since they have paid for the privilege (Ausbrooks et al., 2011). Stork and Hartley (2009) reported more than half of students agreed with a consumer ideology in which students and their parents should have some rights since they pay for their education, while Ausbrooks and associates (2011) found that males and part-time working students were more likely to hold consumerist beliefs. With rising costs of college tuition and resulting student debt and concern over earning power upon graduation, students and parents expect and demand to get a good value for their money (Baker et al., 2008; Gilroy, 2008).

Faculty-related. Academic departments increasingly backfill teaching positions with graduate student instructors and adjuncts in the place of full-time faculty (Corbett, 2019; Frey Knepp, 2012). Unfortunately, higher rates of student incivility are often associated with young, female, low-status adjunct or graduate teaching associates, in addition to faculty members of color and international faculty (Corbett, 2019). Corbett (2019) noted that the stereotypical presentation of college professor as authority figure (i.e., white, male, and American-born) still holds firm in the minds of students, possibly due to lack of representation of faculty of color at the university level. Full-time faculty are often trained as researchers and struggle to effectively engage students or manage their classrooms (Frey Knepp, 2012); their discomfort dealing with conflict may lead them to ignore uncivil classroom behavior, seemingly condoning it and unwittingly increasing the behavior (Ausbrooks et al., 2011).

Faculty need to closely monitor their own belief systems and conduct for signs of uncivil attitudes and behaviors, as faculty incivility oftentimes incites student incivility (Ausbrooks et al., 2011; Robertson, 2012). Bayer (2004) found that faculty who mistreat their students through condescension, inattentive planning, failure to clearly communicate course details/expectations, and personal disregard for students, experience higher incidences of disrespectful student behavior in return. Irrational faculty beliefs also contribute to academic incivility; beliefs that students should be attentive, respectful, and interested at all times, may lead instructors to behave in an uncivil manner, when these unrealistic expectations are violated (Frey Knepp, 2012).

Similar to students, faculty frequently juggle multiple roles with unclear expectations and demanding workloads, leading to significant experiences of stress (Clark et al., 2013; Rawlins, 2017). Stress tends to act as a catalyst, creating environments ripe for incivility from both faculty and students (Rawlins, 2017). Faculty who seem unable to control their emotions - as evidenced by giving dirty looks, yelling, speaking profanely, slinging insults, issuing threats, etc. - are more likely to experience student incivility as well (Robertson, 2012).

Nature of Baby Boomers. In contrast with millennial students, most faculty are from the Baby Boomer generation, born between 1943 and 1960, or the Gen X generation, born 1961-1981 (Ausbrooks et al., 2011; Baker et al., 2008). Baby Boomer instructors tend to value a strong work ethic, adhering to beliefs of work-centrality, and view their millennial students as having a weaker work ethic causing conflict between the groups (Ausbrooks et al., 2011). Generational differences are also evident in communication preferences, with college professors preferring face-to-face contact and students preferring asynchronous communication, such as electronic mail (i.e., e-mail), text messaging, and use of social networking platforms (Bartlett \& Bartlett, 2016). Technology-assisted communication tends to be less formal (e.g., lack of grammar, using slang as shorthand, lack of appropriate honorifics or salutations, using all capital letters to indicate strong emotions, etc.), increasing misunderstandings, and often leading to an incivility spiral between faculty and students (Bartlett \& Bartlett, 2016).

\section{Addressing Incivility}

Addressing incivility must be a collective response, with administrators, educators, and students working together, toward building an educational environment that invites respectful dialogue, safety, and a sense of value for all involved (Corbett, 2019). Faculty must take the lead, acting as transformational leaders (Bass, 1985, 1990; Burns, 1978) and actively model and teach the concept of civility to their students (Baker et al., 2008; Corbett, 2019). Administration can support faculty efforts by developing institution-wide civility codes to be used as a reference when establishing classroom policies; limiting class sizes to no more than 35 students per class, since less 
misconduct occurs in smaller classes; and offering training on how to appropriately address uncivil behaviors (Ward \& Yates, 2014).

Prevention. Incivility is mostly preventable (Robertson (2012), and should not be taken personally, as individuals may not realize how their behavior is perceived by others or understand the negative impact it might have on the teaching-learning environment (Price, 2010). A number of preventative measures have been recommended in order to decrease academic incivility, including (a) assessing civility awareness, (b) using the syllabus, (c) casting classroom policies in a positive light, (d) establishing a code of civility, (e) establishing credibility and "walking the walk," in addition to (f) examining and revising teaching methodologies to be in line with current best practices (Baker et al., 2008; Connelly, 2009; Stork \& Hartley, 2009).

Assessing civility awareness. Connelly (2009) suggests assessing civility awareness on the first day of class in first-year college courses, followed by a similar end-of-class survey to examine changes in perspectives over time and determine effectiveness of civility initiatives. Possible assessments recommended, include:

- The National Survey of Student Engagement for first-year and senior students and the companion faculty survey, and

- Available at http://nsse.indiana.edu/faq/sfaq.cfm

- The Noel-Levitz Student Satisfaction Inventory (Connelly, 2009).

- Available at

https://www.ruffalonl.com/complete-enrollment-management/student-success/student-satisfactionassessment/student-satisfaction-inventory/

Stork \& Hartley (2009) created a 56-item instrument, entitled Student Perceptions of Professor Behavior (SPPB), which assesses student perceptions of offensiveness of professor behaviors, broken down into two different domains (i.e., incompetence and disinterest in teaching, and unwillingness or inability to respect students as individuals).

Using the syllabus. It is important to create well-made syllabi, establishing behavioral standards and rights for both faculty and students, outlining course objectives, and setting clear expectations (i.e., of attendance and exam policies, evaluation methods, tentative course schedules, ground rules for digital civility and communication via technology, and consequences of incivility) with detailed grading rubrics and pedagogical rationales; Faculty should review the syllabus with students on the first day of class to avoid misunderstandings that lead to incivility (Baker et al., 2008; Bartlett \& Bartlett, 2016; Dishon \& Ben-Porath, 2018; Robertson, 2012).

Casting classroom policies in a positive light. Baker et al. (2008) suggests depicting the classroom as an environment to model and practice professional behaviors required in the workplace. Ask students what behaviors would be appropriate/inappropriate in a job interview or a business meeting, for example, and allow adequate time for class discussion. It is also important to make connections between classroom rules, broader university policies, and research literature addressing academic and workplace incivility (Frey Knepp, 2012). Instructors could also consider requiring reading material on the topic (e.g., Choosing Civility by P. M. Forni) for incoming freshmen and transfer students (Ward \& Yates, 2014).

Establishing a code of civility. Academic institutions should create codes of conduct for both faculty and students to follow in order to create a culture of inclusiveness and mutual respect university-wide (Rawlins, 2017). Ward \& Yates (2014) suggests introducing and explaining civility codes at orientation events, and in first-year college courses (see Connelly, 2009 and Pawlowski, 2017 for detailed in-class discussion activities). Faculty and students in individual classes should collaborate on classroom-specific policies, to determine civil classroom behavior; discussion provides in-class experience illuminating such concepts as culture, intergroup dynamics, and conflict resolution relevant to students' lives outside of the educational environment (Baker et al., 2008).

Establishing credibility and "walk the walk." Instructors should always behave courteously and respectfully when interacting with students, seeking to produce closeness and build rapport (Price, 2010). Critical reflection and awareness of behaviors, utilizing a tool such as Clark's Civility Index (Clark, 2013), is important to decrease incidents of incivility in the educational environment (Rawlins, 2017; Russell, 2014). Instructors can establish credibility by learning students' names and calling on them frequently during class; this simple act sends the message that students are seen and valued as individual learners and encourages classroom participation (Frey Knepp, 2012). Students tend to learn by observing faculty role models actively demonstrating professional behaviors, such as: punctuality, dressing appropriately, fair distribution of attention, grading objectively, helping all students perform at their best, and honoring their commitments (Baker et al., 2008; Frey Knepp, 2012; Ward \& Yates, 2014). Faculty 
should also receive training in conflict management strategies, to better assist them in addressing incivility when it occurs, as consistent, immediate enforcement of policies is key to reducing uncivil behaviors (Baker et al., 2008; Frey Knepp, 2012; Plante, 2017).

Examining and revising teaching methodologies. The old lecture-based format of teaching is no longer effective, due to the increasingly technological sophistication of today's students (Baker et al., 2008), but by using a variety of teaching methods, in addition to lecturing (e.g., group work, case studies, video clips, and interactive multimedia), instructors can increase student engagement and therefore, decrease classroom incivility (Price, 2010). Instructors must embrace transformational leadership and grow as educators to meet the needs of students (Baker et al., 2008). Allowing for open and vigorous debate that includes respectful disagreements and improves civility without fear of suppression of free speech (Plante, 2017).

Civility program case study. Project Civility started as a student-led group at a small regional campus in the Midwest, hoping to encourage civility, freedom of expression, and civic participation, in response to uncivil behavior witnessed on campus (Spencer et al., 2016). Project Civility created a social media campaign as a way to notice and thank students and faculty for acts of kindness, the simplest form of civility; wooden nickels the group created would be given to recipients who committed kind acts, and their photograph would then be uploaded to the group's social platforms to inspire future acts in others (Spencer et al., 2016). The group also encouraged civility as democratic participation, by hosting a series of events (e.g., guest speakers, and a series of panel discussions) to encourage and model the dialogic process of respectful disagreement (Spencer et al., 2016). Spencer and associates (2016) noted that the program's panel discussions incorporated a broad array of voices from the local community, including local politicians, members from the chamber of commerce and local school districts, in addition to community and religious leaders representing a variety of ethnicities and religious faiths. This program was seen as a success as it encouraged civility among students and the community at large.

\section{Present Study}

The purpose of the present study was to examine relationships between civility, university identification, and satisfaction with the university.

\section{Method}

\subsection{Participants and Procedure}

Students $\left(N=588,58.7 \%\right.$ female; $\left.M_{\text {age }}=19.20, S D=2.57\right)$ were recruited from various undergraduate classes and asked to rate the perceived civility of other students and faculty toward them, university identification, and satisfaction with the university. Unless noted otherwise, the measures used a 7-point Likert-type response scale, from $1=$ strongly disagree to $7=$ strongly agree .

\subsection{Materials}

Civility. We adapted eight items from prior research (Cortina, Magley, Williams, \& Langhout, 2001) to assess participants' perception that other students and professors were civil in interactions with them. Participants rated four items (e.g., "put down or was condescending") regarding students and the same items again for professors on a 7-point Likert-type response scale, from $1=$ never to $7=$ daily. The items were reversed scored such that higher ratings indicates greater civility $(M=6.08, S D=1.10, \alpha=.89)$.

University identification. We adapted three items (e.g., "I strongly identify with A\&M-Commerce") from prior research (Doosje, Ellemers, \& Spears, 1995; Reysen, Katzarska-Miller, Nesbit, \& Pierce, 2013) to assess participants' degree of identification with the university $(M=5.41, S D=1.54, \alpha=.93)$.

Satisfaction. A single item ("Overall, I am satisfied with my experience at A\&M-Commerce") from prior research (Willcoxson, Cotter, \& Joy, 2011) assessed participants' degree of satisfaction with their experience at the university $(M=5.44, S D=1.61)$.

\section{Results}

As a preliminary analysis, we conducted correlations between the assessed variables. Civility was positively related to university identification $(r=.11, p=.009)$ and satisfaction $(r=.16, p<.001)$, and identification was related to greater satisfaction with the university $(r=.75, p<.001)$. We next tested our hypothesized mediation model using Hayes' (2018) SPSS PROCESS macro (bias-corrected bootstrapping with 20,000 iterations), entering perceived civility as the independent variable, university identification as a mediator, and university satisfaction as the dependent variable (see Figure 1). Civility significantly predicted participants' degree of identification and satisfaction, and university identification predicted satisfaction (see Table 1 for direct and indirect effects). The 
indirect pathway was significantly different from zero as indicated by the lack of zero in the $95 \%$ confidence interval.

\section{Discussion}

Greater civility was found to predict identification and satisfaction with the university. Furthermore, identification with the university was a significant mediator of the association between perceived civility and satisfaction with the university. In effect, low frequency of incivility is associated with feeling a stronger connection with the university and the experience of satisfaction with the university.

\section{Conclusion}

Academic incivility leads to less than optimal teaching-learning environments for both faculty and students, garnering significant concern university-wide. A multitude of civility initiatives, programs, events, student-led organizations, trainings, and interventions hope to combat this complex issue, some of which are mentioned here. The purpose of this literature review was to gain a better understanding of the concept of civility and its counterpart (incivility), associated typologies, and significance of the problem. A thorough review of relevant extant literature revealed numerous potential contributing factors at the student, faculty, and institutional levels. Experiencing acts of incivility, whether first-hand or as a witness, has long-lasting negative effects, necessitating not only preventative measures, but also self-care to strengthen one's sense of resilience against the damages of uncivil behaviors.

\section{References}

Alexander, M. M., \& Mundrake, G. A. (2009). Pre-business college freshman perception of classroom behavior: An analysis among and between genders. The Delta Pi Epsilon Journal, 51(2), 99-116.

Alkandari, N. (2011). The level of student incivility: The need of a policy to regulate college student civility. College Student Journal, 45(2), 257-269.

Altmiller, G. (2012). Student perceptions of incivility in nursing education: Implications for educators. Nursing Education Perspectives, 33, 15-20.

Andersson, L. M., \& Pearson, C. M. (1999). Tit for tat? The spiraling effect of incivility in the workplace. Academy of Management Review, 24(3), 452-471.

Ausbrooks, A. R., Jones, S. H., \& Tijerina, M. S. (2011). Now you see it, now you don't: Faculty and student perceptions of classroom incivility in a social work program. Advances in Social Work, 12(2), 255-275. https://doi.org/10.18060/1932

Baker, S. D., Comer, D. R., \& Martinak, M. L. (2008). All I'm asking' for is a little respect: How can we promote civility in our classrooms?. Organization Management Journal, 5, 65-80. https://doi.org/10.1057/omj.2008.8

Bartlett, M. E., \& Bartlett, J. E. (2016). Case study on the impact of technology on incivility in higher education. The Journal of Educators Online, 13(2), 1-18.

Bass, B. M. (1985). Leadership: Good, better, best. Organizational Dynamics, 13(3), 26-40.

Bass, B. M. (1990). From transactional to transformational leadership: Learning to share the vision. Organizational Dynamics, 18(3), 19-36.

Bayer, A. E. (2004). Promulgating statements of student rights and responsibilities. New Directions for Teaching \& Learning, 99, 77-87.

Berwick, D. M. (1996). A primer on leading the improvement of systems. British Medical Journal, 312, 619-622.

Bjorkund, W. L., \& Rehling, D. L. (2009). Student perceptions of classroom incivility. College Teaching, 58(1), 15-18. https://doi.org/10.1080/87567550903252801

Bourke, B., \& Mechler, H. S. (2010). A new me generation? The increasing self-interest among Millennial college students. Journal of College and Character, 11(2), 1-9. https://doi.org/10.2202/1940-1639.1034

Boychuk Duchscher, J. E., \& Cowin, L. (2004). Multigenerational nurses in the workplace. Journal of Nursing Administration, 43, 493-510.

Boysen, G. A. (2012). Teacher responses to classroom incivility: Student perceptions of effectiveness. Teaching of Psychology, 39(4), 276-279. https://doi.org/10.1177/0098628312456626

Burns, J. M. (1978). Leadership. New York City, NY: harper and Row, Publishers. 
Callahan, J. L. (2011). Incivility as an instrument of oppression: Exploring the role of power in constructions of civility. Advances in Developing Human Resources, 13(1), 10-21. https://doi.org/10.1177/1523422311410644

Center for Survey Research. (2000). A survey on academic incivility at Indiana University. Preliminary report. University of Indiana, Bloomington.

Cialdini, R. B., Kallren, C. A., \& Reno, R. R., (1991). A focus theory of normative conduct: A theoretical refinement and reevaluation of the role of norms in human behavior. Advances in Experimental Social Psychology, 24, 201-234.

Clark, C. (2017). Creating and sustaining civility in nursing education (2nd ed.). Indianapolis, IN: Sigma Theta Tan International.

Clark, C. M., Olender, L., Kenski, D., \& Cardoni, C. (2013). Exploring and addressing faculty-to-faculty incivility: A national perspective and literature review. Journal of Nursing Education, 52(4), 211-218. https://doi.org/10.3928/01484834-20130319-01

Clauson, C., \& McKnight, J. (2018). Welcome to campus: Planning for diversity, inclusion, and equity. Planning for Higher Education, 47(1), 39.

Connelly, R. J. (2009). Introducing a culture of civility in first-year college classes. The Journal of General Education, 58(1), 47-64. https://doi.org/10.1353/jge.0.0029

Corbett, D. R. (2019). Promoting the principles of civility in NAKHE. Quest, 1-10. https://doi.org/10.1080/00336297.2019.1604388

Corey, G. (2013) Theory and practice of counseling and psychotherapy. Monterey, CA: Brooks/ Cole. Cengage Learning.

Cortina, L. M., Magley, V. J., Williams, J. H., \& Langhout, R. D. (2001). Incivility in the workplace: Incidence and impact. Journal of Occupational Health Psychology, 6, 64-80.

Crampton, S. M., \& Hodge, J. W. (2009). Generation Y: Unchartered territory. Journal of Business \& Economic Research, 7(4), 1-6.

Dalton, J., \& Crosby, P. C. (2010). How we teach character in college: A retrospective on some recent higher education initiatives that promote moral and civic learning. Journal of College and Character, 11(2), 1-10. https://doi.org/10.2202/1940-1639.1264

Del Prato, D. (2013). Students' voices: The lived experience of faculty incivility as a barrier to professional formation in associate degree nursing education. Nurse Education Today, 33, 286-290.

Dishon, G., \& Ben-Porath, S. (2018). Don't @ me: Rethinking digital civility online and in school. Learning, Media and Technology, 43(4), 434-450. https://doi.org/10.1080/17439884.2018.1498353

Doosje, B., Ellemers, N., \& Spears, R. (1995). Perceived intragroup variability as a function of group status and identification. Journal of Experimental Social Psychology, 31, 410-436.

Felmann, L. J. (2001). Classroom civility is another of our instructor responsibilities. College Teaching, 49, 137-140.

Forni, P. M. (2002). Choosing civility: The twenty-five rules of considerate conduct. New York: St. Martin's Griffin.

Frey Knepp, K. A. (2012). Understanding student and faculty incivility in higher education. The Journal of Effective Teaching, 12(1), 22-46.

Galbraith, M. W., \& Jones, M. S. (2010). Understanding incivility in online teaching. Journal of Adult Education, 39(2), 1-10.

Ghosh, R., Dierkes, S., \& Falletta, S. (2011). Incivility spiral in mentoring relationships: Reconceptualizing negative mentoring as deviant workplace behavior. Advances in Developing Human Resources, 13(1), 22-39. https://doi.org/10.1177/1523422311410639

Gilroy, M. (2008). Colleges grappling with incivility. The Hispanic Outlook in Higher Education, 18, 8-9.

Hammer, D. (2003). Civility and professionalism. In B. Berger (Ed.). Promoting civility in pharmacy education (pp. 71-90). Binghamton, NY: Pharmaceutical Products Press.

Hard, S. F., Conway, J. M., \& Moran, A. C. (2006). Faculty and college student beliefs about the frequency of student academic misconduct. The Journal of Higher Education, 77, 1058-1080. 
Hayes, A. F. (2018). Introduction to mediation, moderation, and conditional process analysis: A regression-based approach. New York, NY: Guilford Press.

Helm, B., Bonoma, T. V., \&Tedeschi, J. T. (1972). Reciprocity for harm done. Journal of Social Psychology, 87, 89-98.

Jung, C. G., \& Jacobi, J. (1973). C.G. Jung: Psychological reflections: A new anthology of his writings, 1905-1961. Princeton, NJ: Princeton University Press.

Kim, S. H., \& Smith, B. H. (1993). Revenge and conflict escalation. Negotiation Journal, 9, 37-43.

Leiter, M. P., Laschinger, H. K., Day, A., \& Oore, D. G. (2011). The impact of civility interventions on employee social behavior, distress, and attitudes. Journal of Applied Psychology, 1-17. https://doi.org/10.1037/a0024442

Leiter, M. P., Price, S., \& Lachinger, H. (2011). Generational differences in distress, attitudes and incivility among nurses. Journal of Nursing Management, 18, 970-980. https://doi.org/10.1111/j.1365-2834.2010.01168x

Mahvar, T., Farahani, M. A., \& Aryankhesal, A. (2018). Conflict management strategies in coping with students' disruptive behaviors in the classroom: Systematized review. Journal of Advances in Medical Education \& Professionalism, 6(3), 102-114.

Morrissette, P. (2001). Reducing incivility in the university/college classroom. International Electronic Journal of Leadership and Learning, 5(4), 1-13.

Mott, J. (2014). Undergraduate nursing student experiences with faculty bullies. Nurse Educator, 39, 143-148.

Nabila, A. (2011). The level of student incivility: The need of a policy to regulate college student civility. College Student Journal, 45(2), 257-269.

Nordstrom, C. R., Bartels, L. K., \& Bucy, J. (2009). Predicting and curbing classroom incivility in higher education. College Student Journal, 43(1), 64-85.

Pawlowski, D. R. (2017). Communication civility codes: Positive communication through the students' eyes. Communication Teacher, 31(1). https://doi.org/10.1080/17404622.2016.1244344

Plante, T. G. (2017). Making APA civil again: The efforts and outcomes of the civility-working group. Professional Psychology, 48(6), 401-404. https://doi.org/10.1037/pro0000163

Price, C. (2010). Incivility, inattention, and multitasking! Oh my! Creating effective learning environments for millennial learners. In J. Holmes, S. C. Baker, \& J. R. Stowell (Eds.), Essays from Excellence in teaching (pp. 10-14). Danbury, CT: Society for the Teaching of Psychology.

Rawlins, L. (2017). Faculty and student incivility in undergraduate nursing education: An integrative review. Journal of Nursing Education, 56(12), 709-716. https://doi.org/10.3928/01484834-20171120-02

Reysen, S., Katzarska-Miller, I., Nesbit, S. M., \& Pierce, L. (2013). Further validation of a single-item measure of social identification. European Journal of Social Psychology, 43, 463-470.

Robertson, J. E. (2012). Can't we all just get along? A primer on student incivility in nursing education. Nursing Education Perspectives, 33(1), 21-26.

Russell, M. J. (2014). Teaching civility to undergraduate nursing students using a virtue ethics-based curriculum. Journal of Nursing Education, 53(6), 313-319. https://doi.org/10.3928/01484834-20140512-03

Schlenker, B. R. (1980). Impression management: The self-concept, social identity, and interpersonal relations. Monterey, CA: Brooks/Cole Publishing.

Segrist, D., Bartels, L. K., \& Nordstrom, C. R. (2018). "But everyone else is doing it:" A social norms perspective on classroom incivility. College Teaching, 66(4), 181-186. https://doi.org/10.1080/87567555.2018.1482858

Spencer, L. G., Tyahur, P. M., \& Jackson, J. A. (2016). Civility and academic freedom: Extending the conversation. Journal of Contemporary Rhetoric, 6(3/4), 50-61.

Stork, E., \& Hartley, N. T. (2009). Classroom incivilities: Students' perceptions about professors' behaviors. Contemporary Issues in Education Research, 2(4), 13-24. https://doi.org/10.19030/cier.v2i4.1066

Twenge, J. M. (2006). Generation me: Why today's young Americans are more confident, assertive, entitled-and more miserable than ever before. New York: Free Press. 
Twenge, J. M. (2010). A review of the empirical evidence on generational differences in work attitudes. Journal of Business Psychology, 25, 201-210. https://doi.org/10.1007/s10869-010-9156-6

Ward, C., \& Yates, D. (2014). Civility in the university classroom: An opportunity for faculty to set expectations. Contemporary Issues in Education Research, 7(2), 165-170.

Weeks, K. M. (2011). In search of civility: Confronting incivility on the college campus. New York: Morgan James Publishing.

Willcoxson, L., Cotter, J., \& Joy, S. (2011). Beyond the first-year experience: The impact on attrition of student experiences throughout undergraduate degree studies in six diverse universities. Studies in Higher Education, 36, 331-352.

Williams, S. C., \& Lauerer, J. (2013). Implementing a nursing civility code: Implications for education. Journal of Nursing Education, 52(3), 165-170. https://doi.org/10.3928/01484834-20130218-01

\section{Copyrights}

Copyright for this article is retained by the author(s), with first publication rights granted to the journal.

This is an open-access article distributed under the terms and conditions of the Creative Commons Attribution license (http://creativecommons.org/licenses/by/4.0/). 